\title{
STUDY ON THE USAGE STATUS OF EXERCISE EQUIPMENT AND TECHNOLOGIES BY THE INDIVIDUALS PARTICIPATING IN PHYSICAL EXERCISE
}

\author{
Günsel Ana Maria ${ }^{1 *}$ \\ Uluöz Eren ${ }^{2}$ \\ Dinç Zeynep Filiz ${ }^{3}$ \\ ${ }^{1}$ Çukurova University, Sarıçam/Balcalı, Adana 01380, Turkey \\ ${ }^{2,3}$ Cukurova University School of Physical Education and Sport, Turkey
}

Keywords: physical exercise, sports equipment, technology.

\begin{abstract}
The purpose of this study is to determine the usage status of the exercise equipment and technologies by the individuals participating in physical activity. The casual comparative research has been used in this study. The research was carried out on a total of 224 volunteer adults, 138 men and 86 women with an age average of 31,48 +/- 11,19, who participate in regular physical activity. The percentage usage of the equipment during the activity is found to be $73,10 \%$. The evaluation of the equipment usage depending on the sex groups didn't show a difference significant from statistical point of view $\left(x^{2}=0,51\right.$, $\mathrm{df}=1, \mathrm{p}=.822$ ). As a result, the most preferred equipment by the Turkish population shows some similarities with the researches made on other populations. Using the sport equipment it is expected to rise and the gained knowledge is expected to contribute to more efficient exercise workouts and of course to a better public health.
\end{abstract}

\section{Introduction}

Starting with the Industrial Revolution from the beginning of the last century until today the lifestyles and daily habits of people changed rapidly. Technological innovations which record a very fast development led to radical changes in the lives of people from all age groups (Rejeski, Brawley \& Shumaker, 1996). Because of the changes in their lifestyle, people's physical activities reduced and everything that before was done by physical power nowadays is done by machines or technological equipments.

This stable lifestyle caused by technological developments has brought a halt to daily physical activity.

\footnotetext{
*E-mail: anamariagunsel@gmail.com;
} 
These technological developments have a benefit on many areas but led to systematic problems on human health. (US Department of Health and Human Services, 1996; Brady, 1988).

Modern life becomes an inactive lifestyle physical as well as physiological and from psychological and sociological point of view affects the health of people and communities adversely. According to the World Health Organization; thousands of people throughout the world are losing their lives every year because of cardiovascular diseases, diabetes, cancer due to lack of physical activity (Hillsdon et al, 2002; WHO Consultation on Obesity, 2000).

Depression, anxiety, psychological problems such as tiredness and stress also reduce the quality of life of many people today. Many studies have been reported to be effective in solving the psychological problems by participation in physical activity (US Department of Health and Human Services, 1996, Penedo et al., 2005; Bauman, 2006; Daley, Macarthur \& Winter, 2007).

Technological developments have benefits on people in many areas, as well as on individual who practice physical activity and sport. The production of new sport equipment contributes to the practice of a better quality physical activity and plays an important role to the deliberate practice of the physical activities.

Many scientific researches show that the technological developments are strongly used in the fields of physical activities and sports. Many individuals are using different equipments and technological products for different purposes, during physical activity and sport (He, Zhou \& Chen, 2007; Feng \& Jian, 2003).

The most general classification used in the literature is as follows: " technologies and equipments used in direct physical activity"," technologies which determine and enable the monitoring of the physical change" and "technologies which enable the programming of the physical activity"(He, Zhou \& Chen, 2007; Feng \& Jian, 2003).

\section{Material and methods}

Purpose and hypotheses: In this context, the purpose of this research is to determine the usage status of the exercise equipment and technologies by the individuals participating in physical activity. Hypotheses in this study are:

- Hypothesis 1: "There is a significant difference between sex groups on the ratio of evaluation of the equipment usage".

- Hypothesis 2: "There is a significant difference between sex groups on the ratio of evaluation performed on the reasons of not using equipment".

- Hypothesis 3: "There is a significant difference between sex groups on the usage ratio of the technological products during the exercise”. 
- Hypothesis 4: "There is a significant difference between sex groups on the reason of not using of the technological equipment during the exercise".

- Hypothesis 5: "There is a significant difference between sex groups on considering as having enough knowledge regarding the technologies related physical activity".

- Hypothesis 6: "There is a significant difference between sex groups on the desire to be instructed and get more knowledge on the technologies usable during the exercise".

Research model:

The casual comparative research has been used in order to determinate the usage status of the exercise equipment and technologies by the individuals participating in physical activity and the variables associated to these.

Population and sample:

This research was conducted in the central district of Adana in Turkey. The study was conducted among individuals engaged in regular physical activity. 224 adult individuals participated in the study.

The research was carried out on a total of 224 volunteer adults, 138 men and 86 women with an age average of $31,48+/-11,19$, who participate in regular physical activity.

Data collection tools: Participation to the research was voluntary. As data collection tools, in the study it has been used a questionnaire developed by the researcher. The questionnaire consists of 20 questions. In the questionnaire there are questions regarding the demographical characteristics of the participants as well as questions about the equipments and technologies used during the physical activity and exercise.

Data analysis: The results obtained in this study are summarized with descriptive statistics methods as average calculation, standard deviation, frequency, percentage, etc. When analyzing the variables of the research it has been observed that all the data have a normal distribution.

In order to test the significance of the difference between the average of the independent groups, independent $t$ test was used.

For pair groups independent $t$ test and for triple groups Anova test has been used. $\mathrm{p}<0.05$ was considered statistically significant.

\section{Results and Discussions}

The results regarding the demographical characteristics of the individuals who participated to the research are shown on Table 1. 
Table 1. Results regarding some personal characteristics of the individuals participating to the research

\begin{tabular}{|c|c|c|c|c|c|c|}
\hline Sex & Age & Height & Weight & Income & $\begin{array}{c}\text { Exercise } \\
\text { duration } \\
\text { (month) }\end{array}$ & $\begin{array}{c}\text { Weekly } \\
\text { exercise } \\
\text { duration } \\
\text { (day) }\end{array}$ \\
\hline $\begin{array}{c}\text { Women } \\
\text { (n:86) }\end{array}$ & $\begin{array}{c}\text { (no,58 } \\
\pm 10,89\end{array}$ & $\begin{array}{c}165,34 \pm \\
6,78\end{array}$ & $\begin{array}{c}64,09 \pm \\
10,92\end{array}$ & $\begin{array}{c}2827,02 \pm \\
264,03\end{array}$ & $\begin{array}{c}24,74 \pm \\
46,64\end{array}$ & $4,00 \pm$ \\
\hline Men & $32,04 \pm$ & $177,58 \pm$ & $81,14 \pm$ & $3695,74 \pm$ & $50,75 \pm$ & $4,35 \pm$ \\
(n:138) & 11,38 & 10,86 & 11,80 & 284,01 & 84,43 & 1,26 \\
\hline Total & $31,48 \pm$ & $172,88 \pm$ & $74,60 \pm$ & $3362 \pm$ & $41.02 \pm$ & $4.21 \pm$ \\
(n:224) & 11,19 & 11,20 & 14,14 & 279,14 & 73,60 & 1,13 \\
\hline
\end{tabular}

The average age of the participants, as shown in Table 1 is $31.48 \pm 11.19$, the average height is $172.88 \pm 11.20 \mathrm{~cm}$, the average weight is $74.60 \pm 14.14 \mathrm{~kg}$ and the average income level is $3362 \pm 279.14 \mathrm{TL}$.

In addition, it has been found that the regular exercise duration of the participants is $41.02 \pm 73.60$ months, while the weekly exercise duration is 4.21 \pm 1.13 days. The percentage usage of the equipment during the activity is found to be $73,10 \%$.

Hypothesis 1 is rejected. Because the evaluation of the equipment usage depending on the sex groups didn't show a difference significant from statistical point of view $\left(x^{2}=0,51, d f=1, p=.822\right)$.

The reason for not using equipment during the physical activity showed by $87,3 \%$ of the individuals was "participation in activities as jogging, hiking and swimming" while 9,10\% mentioned that they don't use this kind of equipments because "they don't have enough knowledge".

Hypothesis 2 is rejected. As the evaluation performed on the reasons of not using equipment according to sexes didn't show a difference significant from statistical point of view $\left(x^{2}=2,734, d f=2, p=.255\right)$. The most preferred equipment by the individual participants of are shown in Table 2.

As seen in Table 2, the most preferred equipments by the participants are as follows: treadmill (22.19\%), cycling (11.23\%) and Pilates equipment (11.24\%)

The usage ratio of the technological products during the exercise was found to be $38.9 \%$. $62,6 \%$ of the individuals not using technological products stated they found them "not necessary" and $29,1 \%$ of them stated that "they don't have knowledge" about these products. 
Table 2. Distribution of the most preferred equipment by the individual participants

\begin{tabular}{|l|c|c|}
\hline Equipment & $\mathbf{n}$ & $\mathbf{\%}$ \\
\hline Treadmill & 77 & 22.19 \\
\hline Dumbbells and free weights & 74 & 21.32 \\
\hline Pilates equipment & 39 & 11.24 \\
\hline Bicycle & 38 & 10.95 \\
\hline Bicycle ergometer & 32 & 9.22 \\
\hline Complex equipment & 27 & 7.78 \\
\hline Rowing ergometer & 10 & 2.88 \\
\hline Other & 50 & 14.4 \\
\hline Total & $\mathbf{3 4 7}$ & $\mathbf{1 0 0}$ \\
\hline
\end{tabular}

Hypothesis 3 is rejected. Because the evaluation depending on the sex groups didn't show a difference significant from statistical point of view $\left(x^{2}=3,661, d f=2, p=.160\right)$.

On Table 3 there are given the results regarding the reasons mentioned by the participants for not using the technological equipments during the exercise.

Table 3. Results regarding the reasons mentioned by the participants for not using the technological equipments during the exercise

\begin{tabular}{|c|c|c|c|c|}
\hline \multirow[b]{2}{*}{ Sex } & \multicolumn{3}{|c|}{ Reason } & \multirow[b]{2}{*}{ Total } \\
\hline & $\begin{array}{l}\text { I don't like I } \\
\text { think is useless }\end{array}$ & $\begin{array}{l}\text { I don't know } \\
\text { how to use it }\end{array}$ & $\begin{array}{c}\text { I would like to } \\
\text { use but it's } \\
\text { expensive }\end{array}$ & \\
\hline Women & $15(\% 14)$ & $18(\% 16.8)$ & $4(\% 3,7)$ & $\begin{array}{c}37 \\
(\% 34,6)\end{array}$ \\
\hline Men & $52(\% 48,6)$ & $13(\% 12,1)$ & $5(\% 4.7)$ & $\begin{array}{c}70 \\
(\% 65,4) \\
\end{array}$ \\
\hline Total & $67(\% 62,8)$ & $31(\% 29.0)$ & $9(\% 8,4)$ & $\begin{array}{c}107 \\
(\% 100)\end{array}$ \\
\hline
\end{tabular}

$\left(x^{2}=12,347, d f=2, p=.002\right)$

As seen on table $3,62,6 \%$ of the individuals not using technological products stated they found them "not necessary" and $29,1 \%$ of them stated that "they don't have knowledge" about these products. Hypothesis 4 is accepted. As the evaluation depending on the sexes showed a high significance from statistical point of view of the men participants who said that "they don't like to use and they think its useless" compared to the women $\left(\mathrm{x}^{2}=12,347, \mathrm{df}=2\right.$, $\mathrm{p}=.002)$. 
On Table 4 the results regarding the level of knowledge of the participants of the technologies used during the exercise are given.

Table 4. Results regarding the level of knowledge of the participants about the technologies used during the exercise

\begin{tabular}{|c|c|c|c|c|}
\hline \multirow{2}{*}{ Sex } & \multicolumn{3}{|c|}{ Level of knowledge } & \multirow{2}{*}{ Total } \\
\cline { 2 - 4 } Women & Enough & Not enough & Undecided & \\
\hline Men & $65(\% 12.3)$ & $42(\% 19.8)$ & $13(\% 6.1)$ & $\begin{array}{c}81 \\
(\% 38.2)\end{array}$ \\
\hline Total & $91(\% 42.9)$ & $83(\% 39.2)$ & $38(\% 17.9)$ & $\begin{array}{c}131 \\
(\% 61.8)\end{array}$ \\
\hline
\end{tabular}

$\left(x^{2}=9,237, d f=2, p=.010\right)$

As seen on Table 4, 42,90\% of the participants stated that they have enough knowledge regarding the technologies used during exercise, while $39,20 \%$ stated they don't have enough knowledge.

Hypothesis 5 is accepted. Because the evaluation depending on the sexes showed a high significance from statistical point of view of the men participants who said that "they have enough knowledge regarding the technologies" compared to the women $\left(\mathrm{x}^{2}=9,237, \mathrm{df}=2, \mathrm{p}=.010\right)$.

Table 5. Distribution of the participants by the most used exercise technologies

\begin{tabular}{|l|c|c|}
\hline Technologies used during the exercise & $\mathbf{n}$ & $\mathbf{\%}$ \\
\hline Smart phone applications & 75 & 38.08 \\
\hline Pulse measuring instruments & 44 & 22.33 \\
\hline Calories measurement tools & 38 & 19.28 \\
\hline $\begin{array}{l}\text { Physical measurement tools (height, } \\
\text { weight, etc.) }\end{array}$ & 21 & 10.65 \\
\hline Computer software & 19 & 9.65 \\
\hline Total & $\mathbf{1 9 7}$ & $\mathbf{1 0 0}$ \\
\hline
\end{tabular}

As seen on Table 5, the most preferred exercise technologies by the participants are as follows: smart phone applications, pulse measuring instruments, calories measurement tools, physical measuring instruments (height, weight, etc.) and computer software. 
$63,40 \%$ of the participants responded "yes" to the question "Do you want to be instructed and get more knowledge on the technologies usable during the exercise?". Hypothesis 6 is rejected. As the evaluation of the equipment usage depending on the sex groups didn't show a difference significant from statistical point of view $\left(\mathrm{x}^{2}=1,740, \mathrm{df}=2, \mathrm{p}=.419\right)$.

\section{Discussions}

The development of sports equipment is significantly increasing as technology nowadays is rapidly developing. According to Gu Chen (2008), a sustainable development is seen based on the research and production processes of sports equipment. Scientific Research on exercise-associated equipment, has been shown to positively impact to physical activity (Rosenberg et al., 2010).

However, there have been conducted some studies regarding the determination of the equipments to be used by the individuals (Robinson, 1999; Trost et al., 2001; Bryant et al., 2008; Sirard et al., 2008).

In this study, equipment usage rate was found to be $73.10 \%$ and the most preferred equipment by the participants is as follows: treadmill, dumbbells and free weights, Pilates equipment, bicycle and bicycle ergometer. Rosenberg and colleagues (2010) found a rate of the equipment owned by the participants of $82 \%$. applications are seen as the most commonly used technology (Robert et al., 2007).

However, the most preferred exercise reported is bicycle, roller skates, aerobic equipment, dumbbells, and water sports equipment. It is also natural to have different preferences for equipment in different communities. Exercises of technological development and physical activity have been reported in many scientific research is widely used (Dytell, Trent \& Conway, 1991; Tate, Wing \& Winett).

Also in this study the rate of the usage of technological products was found to be $38,9 \%$ and the most common technologies used were determined to be the smart mobile phone applications, Pulse measurement tools, Calorie measuring instruments, physical measuring instruments (height, weight, etc.) and computer software.

When analysing the studies in the literature, the most used technologies are the weight loss programs within the internet technology (Tate, Wing \& Winett, 2001), pedometer (Bouten et al., 1997) speed measuring instruments (Boutin et al., 1997), calorie measurement instruments (Kumahar et al., 2004), anthropometric measurement tools and mobile phone applications.

\section{Conclusions}

As a result, the most preferred equipment by the Turkish population shows some similarities with the researches made on other populations.

The technological equipment used to exercise and physical activity also shows similarities. Studies in the literature have shown that the usage of the equipment and technology during the exercise and physical activity has positive effects on individuals. 
A great majority of the individuals participating in the study reported that they don't have enough knowledge about the use of relevant technology and exercise.

However, almost all of the individuals who declare that they don't have enough knowledge mentioned that they would like to have the chance to get an instruction on this issue and stated that they want to participate in this training in order to increase their knowledge on this subject.

In this context, with the support of the public health institutions, the number of the people who want to participate in physical activity as well as the number of individuals who want to be instructed in order to use the sport equipment it is expected to rise, and the gained knowledge is expected to contribute to more efficient exercise workouts and of course to a better public health.

\section{References}

1. BAUMAN, A.E. (2004). Updating the evidence that physical activity is good for health: an epidemiological review, Journal of Science and Medicine in Sport, 1 (7), Supplement 1, 6-19, Australia;

2. BOUTEN C.V., KOEKKOEK K.T., VERDUIN M., KODDE R., JANSSEN J.D. (1997). A triaxial accelerometer and portable data processing unit for the assessment of daily physical activity, IEEE Trans Biomed Eng., 3 (44), 136-47, Netherlands;

3. BRADY, F. (1998). The Role Of Physical Activities Throughout The Lifespan: Implications for counselors and teachers, Journal of Humanistic Education \& Development, 4 (36), 234-247, USA;

4. BRYANT M.J., WARD D.S., HALES D., VAUGHN A., TABAK R.G., STEVENS J. (2008). Reliability and validity of the healthy home survey: A tool to measure factors within homes hypothesized to relate to overweight in children, Int J Behav Nutr Phys Act, 5 (23), United Kingdom;

5. DALEY A.J., MACARTHUR C. WINTER H. (2007). The role of exercise in treating postpartum depression: a review of the literature, J Midwifery Womens Health; 52, 56-62, United Kingdom;

6. ROSENBERG, D. E., SALLIS, J. F., KERR, J., MAHER, J., NORMAN, G. J., DURANT, N., \& SAELENS, B. E. (2010). Brief scales to assess physical activity and sedentary equipment in the home. Int $J$ Behav Nutr Phys Act, 7(10), 1-11, USA;

7. DYTELL, R. S., TRENT, L. K., \& CONWAY, T. L. (1991). A causal analysis of interrelationships among exercise, physical fitness, and wellbeing in US Navy personnel. Naval Health Research Center, NHRC-91-27, SAN DIEGO CA, USA;

8. HE, B., ZHOU, L. J., \& CHEN, X. Y. (2007). Study on the International Competitiveness of Chinese Sporting Goods Industry [J]. China Sport Science, 27(7), 1-5, China; 
9. HILLSDON M., THOROGOOD M., WHITE I., FOSTER C. (2002). Advising people to take more exercise is ineffective: a randomized controlled trial of physical activity promotion in primary care, Int.J.of Epidemiol, 31(4), 808-815, United Kingdom;

10. KUMAHARA, H., SCHUTZ, Y., AYABE, M., YOSHIOKA, M., YOSHITAKE, Y., SHINDO, M. \& TANAKA, H. (2004). The use of uniaxial accelerometry for the assessment of physical-activity-related energy expenditure: a validation study against whole-body indirect calorimetry. Br J Nutr., 2 (91), 235-43, Switzerland;

11. PENEDO, F. J., \& DAHN, J. R. (2005). Exercise and well-being: a review of mental and physical health benefits associated with physical activity. Current Opinion in Psychiatry, 18(2), 189-193, USA;

12. PINTO B.M., FRIEDMAN R., BESS H.M, KELLEY H., TENNSTEDT S., GILLMAN M. W. (2002). Effects of a computer-based, telephonecounseling system on physical activity, Am J Prev Med., 2 (23), 113-120, USA;

13. HURLING R., CATT M., DE BONI M., FAIRLEY B.W., HURST T., MURRAY P., RICHARDSON A., SINGH SODHI J. (2007). Using Internet and Mobile Phone Technology to Deliver an Automated Physical Activity Program: Randomized Controlled Trial, J Med Internet Res., 2 (9), 7, United Kingdom;

14. ROBINSON T. N. (1999). Reducing children's television viewing to prevent obesity: a randomized controlled trial, Jama, 282, 1561-1567, USA;

15. SIRARD J.R., NELSON M.C., PEREIRA M.A., LYTLE L.A. (2008). Validity and reliability of a home environment inventory for physical activity and media equipment, Int J Behav Nutr Phys Act, 5(1), 24, USA;

16. TATE D.F., WING R.R., WINETT R.A. (2001). Using Internet technology to deliver a behavioural weight loss program, Jama, 7, 285 (9): 1172-1177, USA;

17. TROST S.G., KERR L.M., WARD D.S., PATE R.R. (2001). Physical activity and determinants of physical activity in obese and non-obese children, Int J Obes Relat Metab Disord, 25(6): 822-829, USA;

18. TUDOR C.L., BASSETT D.R, SWARTZ A.M., STRATH S.J, PARR B.B, REIS J. P., DUBOSE K.D., AINSWORTH B.E. (2004). A preliminary study of one year of pedometer self-monitoring, Ann Behav Med. Dec., 3 (28), 158-162, USA;

19. SATCHER D. (G.D). (1996). U.S. Department of Health and Human Services. Physical activity and health: a report of the surgeon general, U.S. $J$ Centers for Disease Control and Prevention, Atlanta, GA, USA;

20. REJESKI W.J., BRAWLEY L.R., SHUMAKER S.A. (1996), Physical activity and health-related quality of life. Exerc Sport Sci. Rev., 24(1), 71108, USA; 
21. World Health Organization. (2000). Consultation on Obesity. Obesity: Preventing and Managing the Global Epidemic. World Health Organization; WHO Technical Report Series, 268-294, Switzerland;

22. YOSHIOKA M., AYABE M., YAHIRO T., HIGUCHI H., HIGAKI Y., ST-AMAND J., MIYAZAKI H., YOSHITAKE Y., SHINDO M., TANAKA H. (2005). Long-period accelerometer monitoring shows the role of physical activity in overweight and obesity, Int J Obes (Lond), 29(5): 502-508, Japan;

23. FENG Y.D., JIAN G. (2003). Retrospect and Prospect of Sports Instrument Subjects in the Past 20 Years in China [J], China Sport Science and Technology, 3(1), 222-228, China;

24. CHEN GU. (2007). Strategies on the Sustainable Development of Sports Equipments Research and Manufacture in China [J]. Journal of Beijing Sport University, 8 (1), 4-9, China. 